\title{
Three Year Community Based Intervention for Chronic Disease Prevention in Epidemiological and Political Transition Context: Example of Tunisia
}

\author{
Jihen Maatoug1 ${ }^{*}$, Imed Harrabi ${ }^{1}$, Rafika Gaha1 ${ }^{1}$ Larbi Chaieb ${ }^{2}$, Nejib Mrizek ${ }^{3}$, Souad Amimi ${ }^{4}$, \\ Lamia Boughammoura5, Gouider Jeridi6, Habib Gamra7, Hassen Ghannem ${ }^{1}$ \\ ${ }^{1}$ Department of Epidemiology, University Hospital Farhat Hached, Sousse, Tunisia \\ ${ }^{2}$ Department of Endocrinology, University Hospital Farhat Hached, Sousse, Tunisia \\ ${ }^{3}$ Department of Occupational Medicine, University Hospital Farhat Hached, Sousse, Tunisia \\ ${ }^{4}$ Group of Occupational Health of Sousse, Sousse, Tunisia \\ ${ }^{5}$ Department of Pediatrics, University Hospital Farhat Hached, Sousse, Tunisia \\ ${ }^{6}$ Department of Cardiology, University Hospital Farhat Hached, Sousse, Tunisia \\ ${ }^{7}$ Department of Cardiology, University Hospital Fattouma Bourguiba, Monastir, Tunisia \\ Email: ${ }^{*}$ ihenmaatoug3107@gmail.com
}

Received 24 June 2015; accepted 4 August 2015; published 7 August 2015

Copyright (C) 2015 by authors and Scientific Research Publishing Inc.

This work is licensed under the Creative Commons Attribution International License (CC BY).

http://creativecommons.org/licenses/by/4.0/

(c) (i) Open Access

\section{Abstract}

Objective: Our aim was to determine the effectiveness, feasibility, and necessary cultural adaptations of evidence-based interventions directed at tobacco use, unhealthy diet, and physical inactivity in adults and children in three different sectors: workplace, neighborhood and schools. Materials and Methods: We conducted in Sousse, Tunisia an interventional study through a quasiexperimental design (pre-post with intervention and control groups) to prevent non communicable disease risk factors. The intervention group included different settings and pre and post assessment concerned independent groups (schools with 1929 and 2170 participants, workplaces with 914 and 1098 participants and community with 940 and 1001 participants respectively at pre and post assessment). It was located in the delegation of Sousse Jawhara and Sousse Erriadh. The control group with similar settings (schools with 2074 and 2105 participants, workplaces with 861 and 1015 and community with 940 and 976 participants respectively at pre and post assessment) was located in the delegation of Msaken from the region of Sousse. Results: Tobacco use decreased among neighborhood $(26.2 \%$ to $23.2 \%, p=0.13)$ workplace $(39.2 \%$ to $37.5 \%, p=0.43)$ and schools $(5.7 \%$ to $4.8 \%, p=0.19)$ participants. In control group, it increased significantly in

${ }^{*}$ Corresponding author.

How to cite this paper: Maatoug, J., et al. (2015) Three Year Community Based Intervention for Chronic Disease Prevention in Epidemiological and Political Transition Context: Example of Tunisia. Open Journal of Preventive Medicine, 5, 321-329. http://dx.doi.org/10.4236/ojpm.2015.58036 
schools and neighborhood. Participants who consumed five fruits and vegetables daily increased significantly in all settings in intervention group (from $30 \%$ to $33.2 \%$ in schools, $47.5 \%$ to $52.1 \%$ in workplace and $39.4 \%$ to $58.4 \%$ in neighborhood). However in control group it increased only in schools and neighborhood. An improvement in physical activity practice was seen both in intervention and control group among adults participants but not in schools. Conclusion: The "Together in Health" project for the prevention of risk factors for NCD is an example of a loco-regional initiative. Such initiatives can only be beneficial with a structure organized by the government.

\section{Keywords}

Prevention, Risk Factor, Chronic Disease, Adult, School, Community

\section{Introduction}

According to the World Health Organization (WHO), chronic diseases are responsible for 36 million deaths in 2008 [1]. Chronic diseases known as non-communicable diseases (NCDs) include mainly cardiovascular diseases, cancers, diabetes and chronic respiratory diseases [1].

The global epidemic of NCDs was responsible for $63 \%$ of all deaths, including at least one quarter before the age of 60 . The NCD deaths are projected to increase by 15\% overall between 2010 and 2020 (to reach 44 million deaths). Only $20 \%$ of these deaths occurred in high-income countries, while $80 \%$ occurred in the low-income and middle-income countries. The expected number of deaths from NCDs will increase from 35 million in 2005 to 41 million in 2015, at the same time, years of life lost adjusted for disability (DALYs) will increase from 725 to 808 million [2].

Like most North African and Arab countries, Tunisia, is going through an epidemiologic transition [3] with rising of life expectancy and adoption of new lifestyles that lead to NCDs. This transition has been well described, particularly the recent increase in diabetes and risk factors for cardiovascular disease [4] [5]. Statistics on causes of death in Tunisia in 2009, showed that CVD ranks first with 28.9\% of all recorded deaths [6]. In a study on the trend of mortality from ischemic heart disease in Tunisia between 1997 and 2009 [7], the mortality rate from coronary causes increased by $11.8 \%$ for men and $23.8 \%$ for women. Thus, Tunisia is now facing the pronounced emergence of NCDs, hence the need to prepare an integrated prevention strategy to address common risk factors and major determinants shared by NCDs [8]. Four preventable risk factors: tobacco use, unhealthy diet, physical inactivity and harmful use of alcohol play a dominant and often synergistic role in the development of these NCDs. This means that integrated actions against these risk factors implemented in the social context can lead to the reduction of major chronic diseases [9]. These lifestyle risk factors are important not only for their etiological significance but also because they are modifiable risk factors and at the distal end of the causal chain, which means there is greater opportunity for their prevention [10] [11].

Most of what we know about the prevention of NCDs comes from the experience of developed countries where many of these diseases have been the object of successful interventions. This includes for example the Pawtucket Heart Health program of the United States of America and the Isfahan Healthy Heart program in Iran [12]-[15]. Valuable lessons have been learned from the implementation of projects in developed countries [16] and evaluation of various community-based interventions that adopted multisectoral approach [17].

The concept of integrated NCD prevention as an essential component of existing health system with a focus on health promotion at the population level could be the way that our country must take to significantly reduce the future epidemic of these diseases.

The project "Together in Health" is an example of an integrated chronic disease prevention programme in an intersectoral approach that goes beyond the health care system. It was implemented by the Chronic Disease Prevention Research Center in Sousse Tunisia with the partnership of different academic departments from Farhat Hached University Hospital, with different regional authorities (Health, Education, Youth and physical activities) and NGOs (Tunisian Heart Foundation). At international level, the centre has partnered with the Institute of Health and Welfare in Helsinki, Finland, and its programme broadly follows the North Karelia project in Finland [18] that was associated with dramatic falls of age adjusted mortality rates from coronary heart dis- 
ease among men aged 35 to 64 years [18]. The centre is also partnering with Duluth Medical research Institute at University of Minnesota.

Our aim was to determine the effectiveness, feasibility, and necessary cultural adaptations of evidence-based interventions directed at tobacco use, unhealthy diet, and physical inactivity in adults and children in three main sectors: workplace, neighbourhood and workplace.

\section{Materials and Methods}

\subsection{Study Design}

We conducted in Sousse, Tunisia an interventional study through a quasi-experimental design (pre-post with intervention and control groups). The intervention group included different settings (schools, workplaces and neighborhood) was located in the delegation of Sousse Jawhara and Sousse Erriadh. The control group with similar settings was located in the delegation of Msaken from the region of Sousse (Figure 1).

\subsection{Studied Populations}

The studied populations were composed, in school settings from schoolchildren of colleges of Sousse aged 11 to 16 years old in $7^{\text {th }}$ and $9^{\text {th }}$ grade, in workplaces from workers in 6 enterprises with 3 in intervention and 3 in control group and in the community from adults aged 18 to 65 years in households from delegations of Sousse Jawhara, Sousse Riadh and Msaken.

Sample size calculation in the different settings were based on a significance level of $\alpha=0.05 \%$, power of test $\beta=20 \%$, two sided test of hypothesis and $6 \%$ change in risk factors levels (smoking, unhealthy diet and physical inactivity) giving a total sample of 4000 schoolchildren in school settings, 2000 workers in workplaces and 2000 adults from households in communities.

For the school and community settings, the pre and post-assessment concerned random samples from these settings, while in workplace, we selected a convenience sample of 3 enterprises in the intervention and 3 enterprises in the control group with similar characteristics regarding the total number of workers and sex composition.

In schools, the intervention group and control group were randomly selected from all colleges of the intervention and control zones respectively with nine schools selected in the intervention and 8 schools selected in the control group. In the community, we randomly selected 500 households in the intervention and control group respectively and included all adults aged 18 years and more in these households.

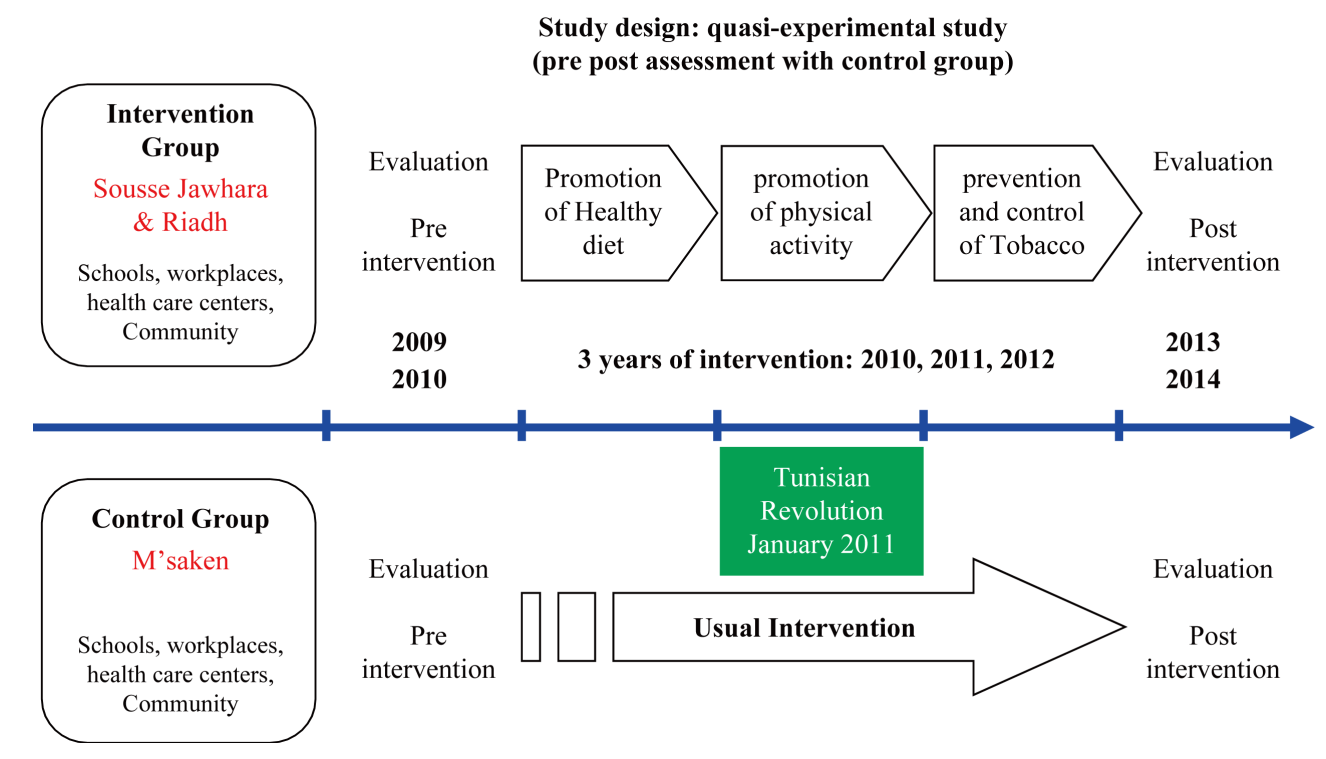

Figure 1. Study design of three year community based intervention for chronic disease prevention in Sousse Tunisia. 


\subsection{Data Collection}

We used a pretested and standardized questionnaire to evaluate knowledge of, attitudes towards and beliefs on the three risk factors for chronic disease: unhealthy diet, physical inactivity and tobacco use. We also collected biometric measures such as height, weight and waist circumference in three settings.

The questionnaire was self-administered in schools with the presence of trained medical doctors to assist filling out the questionnaires. It was administered by interview in workplaces and households. All questionnaires were completed anonymously.

\subsection{Variable Definition}

To define overweight and obesity among schoolchildren, we used the recent international cut-off values of BMI according to age and sex [19].

Definition of smoker: Among adults, we asked participants, "Do you currently smoke any tobacco products, such as cigarettes, cigars, or pipes?” Smokers were the participants who responded yes to this question. Among adolescents, smoker is the person who smoked at least one cigarette last month among adolescent [20]. The recommended level of physical activity was used as defined by the WHO for children and adults [21].

\subsection{Intervention Program}

The intervention program was prepared by the project team to address chronic disease risk factors. In this program we were coached and trained by a team from north Karelia project (Finland) and the actions were adapted to our context.

School based intervention program consisted mainly on the creation of leaders groups among teachers and schoolchildren. Then, education sessions were animated by teachers about physical activity and healthy diet promotion and tobacco use prevention, workshops were organized by the team of the project and schoolchildren leaders in each school with the presence of parents on three different topics tobacco prevention and physical activity and healthy diet promotion. We also organized sports tournament intra and inter colleges and offered free management of obesity in schools.

Intervention program in the workplace consisted mainly on the projection of educative film for employees and interactive educative sessions with the occupational physician, workshops animation about healthy diet and motivation to quit smoking, an open sensitization days in workplaces with three different topics (smoking, physical activity, diet), free physical activity sessions for employees and free smoking cessation consultation in workplace.

Intervention program in neighborhood consisted mainly on open sensitization days on three different topics (smoking, physical activity, diet), distribution of flyers, animation of radio sessions to promote healthy diet and physical activity and to control tobacco use.

\subsection{Data Analyses}

Statistical analysis was performed using the SPSS 10.0 software. We used descriptive statistics (frequencies, means and standard deviation) and chi square test to compare percentages with 0.05 as a level of significance.

\subsection{Ethical Consideration}

This study was undertaken with respect of the rights and integrity of people. For schoolchildren, parents gave their informed consent. We obtained approval from University Hospital Farhat Hached ethical committee.

For adults in households and workplaces, we obtained an informed consent. The intervention consisted on educational messages which haven’t any harmful consequences.

\section{Results}

In schools, number of participants was respectively at pre and post assessment 1929 and 2170 in intervention group and 2074 and 2105 in control group. The proportion of boys was respectively at pre and post assessment $50.2 \%$ and $48.7 \%$ in intervention group $(p=0.35)$ and $46.5 \%$ and $47.7 \%$ in control group ( $p=0.45)$. In workplace, number of participants was respectively at pre and post assessment 914 and 1098 in intervention 
group and 861 and 1015 in control group. The proportion of males was respectively at pre and post assessment $64.7 \%$ and $65.5 \%$ in intervention group $(\mathrm{p}=0.7)$ and $59 \%$ and $61.4 \%$ in control group $(\mathrm{p}=0.29)$. In neighborhood, number of participants was respectively at pre and post assessment 940 and 1001 in intervention group and 940 and 976 in control group. The proportion of males was respectively at pre and post assessment $43.2 \%$ and $44.2 \%$ in intervention group ( $\mathrm{p}=0.67)$ and $28.8 \%$ and $34.3 \%$ in control group $(\mathrm{p}=0.01)$ (Table 1$)$.

In schools, the proportion of schoolchildren who consume 5 fruits and vegetables improves significantly in intervention group from $30 \%$ to $33.2 \%(\mathrm{p}=0.027)$. Tobacco use and overweight decreased in intervention group but not significantly however in control group it increased significantly in control group (Table 2).

In workplace, the participants who do recommended level of physical activity and consume 5 fruits and vegetables daily increased significantly in intervention group. Proportion of hypertension and obesity decreased significantly in intervention group and increased significantly in control group (Table 3).

In neighborhood, the participants who do recommended level of physical activity and consume 5 fruits and vegetables daily increased significantly both in intervention and control group. Tobacco use decreased not significantly in intervention group but increased significantly in control group. Hypertension decreased significantly in intervention group (Table 4).

\section{Discussion}

Community interventions in "Together in Health" program were successful in improving some lifestyle and NCDs risk factors. To improve the effectiveness and feasibility of our program, several society actors have been targeted in their respective sectors such as children in schools and adults in the workplace. Shea et al. [22] in a review of five programs for the prevention of cardiovascular disease throughout the community have identified

Table 1. Socio demographic characteristics in intervention and control groups at pre and post assessment.

\begin{tabular}{|c|c|c|c|c|c|}
\hline & & \multicolumn{2}{|c|}{ Intervention group } & \multicolumn{2}{|c|}{ Control group } \\
\hline & & Pre assessment & Post assessment & Pre assessment & Post assessment \\
\hline \multirow{3}{*}{ Schools } & Response rate & 1929 (93.1) & 2170 (91.9) & $2074(96.0)$ & 2105 (93.9) \\
\hline & Sex (boys) n (\%) & $968(50.2)$ & 1045 (48.7) & 965 (46.5) & $1003(47.7)$ \\
\hline & Age mean (SD) & $13.2(1.2)$ & $13.2(1.2)$ & $13.4(1.3)$ & $13.3(1.2)$ \\
\hline \multirow{3}{*}{ workplace } & Response rate & $914(76.7)$ & 1098 (67.5) & 861 (72.5) & 1015 (77.5) \\
\hline & Sex (men) n (\%) & $591(64.7)$ & 719 (65.5) & $508(59.0)$ & $623(61.4)$ \\
\hline & Age mean (SD) & $32.2(8.1)$ & $33.8(8.1)$ & $35.4(8.7)$ & $38.9(8.8)$ \\
\hline \multirow{3}{*}{ Neighborhood } & Response rate & $940(73.5)$ & $1001(74.3)$ & $940(73.1)$ & $976(62.5)$ \\
\hline & Sex (men) n (\%) & $406(43.2)$ & $442(44.2)$ & $271(28.8)$ & 335 (34.3) \\
\hline & Age mean (SD) & $37.2(13.2)$ & 39.2 (13.6) & $38.6(13.7)$ & $40.4(13.9)$ \\
\hline
\end{tabular}

Table 2. Results of intervention to prevent NCDs risk factors in school setting in the region of Sousse Tunisia.

\begin{tabular}{ccccccc}
\hline & \multicolumn{3}{c}{ Intervention group } & & & Control group \\
\cline { 2 - 7 } & $\begin{array}{c}\text { Pre assessment } \\
\mathrm{n}(\%)\end{array}$ & $\begin{array}{c}\text { Post assessment } \\
\mathrm{n}(\%)\end{array}$ & $\mathrm{p}$ value & $\begin{array}{c}\text { Pre assessment } \\
\mathrm{n}(\%)\end{array}$ & $\begin{array}{c}\text { Post assessment } \\
\mathrm{n}(\%)\end{array}$ & $\mathrm{p}$ value \\
\hline $\begin{array}{c}\text { Do recommended level } \\
\text { of physical activity }\end{array}$ & $554(29.1)$ & $536(25.5)$ & 0.01 & $434(21.1)$ & $425(21.2)$ & 0.88 \\
$\begin{array}{c}\text { Consume } 5 \text { fruits and } \\
\text { vegetable daily }\end{array}$ & $565(30.0)$ & $702(33.2)$ & 0.027 & $821(40.2)$ & $695(35.0)$ & 0.001 \\
$\begin{array}{c}\text { Consume tobacco } \\
\text { Obese or overweight }\end{array}$ & $110(5.7)$ & $104(4.8)$ & 0.19 & $155(7.5)$ & $193(9.2)$ & 0.048 \\
\hline
\end{tabular}


Table 3. Results of intervention to prevent NCDs risk factors in workplace setting in the region of Sousse Tunisia.

\begin{tabular}{ccccccc}
\hline & \multicolumn{3}{c}{ Intervention group } & \multicolumn{3}{c}{ Control group } \\
\cline { 2 - 7 } & $\begin{array}{c}\text { Pre assessment } \\
\mathrm{n}(\%)\end{array}$ & $\begin{array}{c}\text { Post assessment } \\
\mathrm{n}(\%)\end{array}$ & p value & $\begin{array}{c}\text { Pre assessment } \\
\mathrm{n}(\%)\end{array}$ & $\begin{array}{c}\text { Post assessment } \\
\mathrm{n}(\%)\end{array}$ & p value \\
\hline $\begin{array}{c}\text { Do recommended level } \\
\text { of physical activity }\end{array}$ & $253(28.3)$ & $414(37.9)$ & $<0.001$ & $262(31.2)$ & $626(42.9)$ & $<0.001$ \\
$\begin{array}{c}\text { Consume } 5 \text { fruits and } \\
\text { vegetable daily }\end{array}$ & $421(47.5)$ & $558(52.1)$ & 0.04 & $504(60.9)$ & $613(62.2)$ & 0.57 \\
$\begin{array}{c}\text { Consume tobacco } \\
\text { Obese or overweight }\end{array}$ & $350(39.2)$ & $410(37.5)$ & 0.43 & $250(31.7)$ & $308(30.6)$ & 0.62 \\
Hypertension & $435(47.6)$ & $615(56.0)$ & $<0.001$ & $509(59.1)$ & $693(68.3)$ & $<0.001$ \\
\end{tabular}

Table 4. Results of intervention to prevent NCDs risk factors in neighborhood in the region of Sousse Tunisia.

\begin{tabular}{|c|c|c|c|c|c|c|}
\hline & \multicolumn{3}{|c|}{ Intervention group } & \multicolumn{3}{|c|}{ Control group } \\
\hline & $\begin{array}{c}\text { Pre assessment } \\
\mathrm{n}(\%)\end{array}$ & $\begin{array}{c}\text { Post assessment } \\
\mathrm{n}(\%)\end{array}$ & $\mathrm{p}$ value & $\begin{array}{c}\text { Pre assessment } \\
\mathrm{n}(\%)\end{array}$ & $\begin{array}{c}\text { Post assessment } \\
\mathrm{n}(\%)\end{array}$ & $\mathrm{p}$ value \\
\hline $\begin{array}{c}\text { Do recommended level } \\
\text { of physical activity }\end{array}$ & 141 (15.1) & $400(40.1)$ & $<0.001$ & $141(15.0)$ & 375 (38.5) & $<0.001$ \\
\hline $\begin{array}{l}\text { Consume } 5 \text { fruits and } \\
\text { vegetable daily }\end{array}$ & 368 (39.4) & $579(58.4)$ & $<0.001$ & $483(51.4)$ & $663(67.9)$ & $<0.001$ \\
\hline Consume tobacco & $242(26.2)$ & 232 (23.2) & 0.13 & $135(14.4)$ & $178(18.3)$ & 0.02 \\
\hline Obese or overweight & $580(61.7)$ & $656(65.5)$ & 0.79 & $578(61.5)$ & $642(65.8)$ & 0.05 \\
\hline Hypertension & $325(35.8)$ & 311 (31.4) & 0.04 & 274 (29.3) & $296(30.3)$ & 0.625 \\
\hline
\end{tabular}

effective strategies for community mobilization: social marketing, education program in middle school and in the workplace, screening and referral of high-risk individuals, the education of health professionals and changes in physical environments. Thus, it is necessary to identify key stakeholders for effective intervention mainly to adapt environment because it's an important determinant of health [23].

The school is a privileged area that can target a large number of young people. The intervention implemented in Finland since 1978 in the community has, in fact, included a school-based intervention "The North Karelia Youth Project” [24]. This intervention improved eating habits and lipid parameters after two years of intervention. For smoking habits, intervention could be effective long after. This was explained by the social approach combined with the involvement of the media and the community intervention conducted concomitantly [18] [24]. Thus, to have a successful school program, it must be combined with other community actions and have a fairly long period of intervention; this was also observed in the program of Isfahan in Iran [15].

Parental involvement can be done in schools but also in the context of interventions programs in occupational settings where adults spend most of their time. The work environment has potentially important effects on the behaviour of workers' health and risk factors for several diseases [25] [26]. Therefore, the WHO states that the importance of health promotion in the workplace is increasingly recognized [27]. Recent research has shown that effective programs were those that offered multiple interventions on risk factors combined with a combination of group and individual education [28]. These programs have been successful on both the health of employees [28] but also with a decrease in the cost of health care needs [29]. Moreover, this benefit may be an argument to convince employers of the benefits of these actions and make them relevant and acceptable programs for employees. Indeed, effective interventions for health promotion in the workplace depend in part on the interest and willingness of employers to support these programs and employees to participate [30].

Guidelines for health promotion in the workplace suggest that these programs should be given at different levels to facilitate sustainable behavior change. At the individual level, a program should include several educational strategies. At the organizational level, employers and the various agencies such as the occupational health 
should strengthen and encourage positive action on health (for example, by providing healthy food options in the cafeteria). Finally, at the community level, these programs of health promotion in the workplace can be actively disseminated by employees to their families and social networks [31] and represent a major component of interventions at the community level.

During the last two decades, we have noticed an increased interest in interventions to promote health at the community level. This is due to the fact that risk factors for non communicable diseases are determined by individual behaviors that themselves depend largely on social and environmental context. This has led many researchers and public health professionals to implement actions and compains to change not only individual behavior but also social norms, public policy and physical environment [32]. These programs have so many advantages as they target the population on a large scale and therefore have great potential to improve the level of risk and morbidity in the general population rather than approaches that target only a small proportion of at high risk patients [33].

Among the most effective interventions, one can cite the example of Finland [18], that started from the 70s in North Karelia formulated and implemented to carry out a comprehensive intervention through community organizations with the action of the population itself. Multisectoral actions were used, involving health and other services, schools, NGOs, media campaigns, local media, supermarkets, food industry, agriculture and legislation. The main results of this integrated intervention program is the decline in mortality from ischemic heart disease in people under 65 by $73 \%$ after 25 years of intervention. Risk factors for cardiovascular disease have also decreased, such as smoking, cholesterol, blood pressure with an increased use of vegetable oils rather than butter.

The revolution context in Tunisia which coincided with the intervention period of our projects made structural changes difficult to achieve because of other competing priorities and turnover of the main stakeholders involved in the different settings.

This is the first intervention at the community level done in Tunisia through a quasi-experimental research design with a control group and power based samples. However, the absence of randomization in this case could be the cause of non comparability of the two groups representing then a certain limit in this study. But more important than the comparability between the two groups is, rather to be considered, the comparability intra group before and after the intervention. Furthermore, we admit the quasi experimental design couldn't confirm that observed changes were due to intervention program.

The intervention lasted three years. This time duration may seem limited compared to other international studies, however we do not have other studies with such an important time in Tunisia especially as the conditions under which the intervention took place with the occurrence of the Tunisian revolution in the middle of the project that increased the efforts to involve new leaders and adapt to the new socio-political conditions.

The socio-political conditions after the revolution also made it that the authorities and policy makers at the Ministry of Health and other sectors (Ministry of Interior, education, finance, urban design...) had other priorities and challenges than the fight against non-communicable diseases and their risk factors. Thus, multi-sectoral and structural measures that are most important in this area were very limited in our program given the circumstances described above.

\section{Conclusion}

The "Together in Health" project for the prevention of risk factors for NCD is an example of a loco-regional initiative. This initiative has shown that it is possible to design and implement activities to promote health in various settings with the support of the community. Such initiatives can only be beneficial if they became widespread in oil stains manner within a structure organized by the government.

\section{Acknowledgements}

This paper was based on a project funded by "United Health Group" and by the Research Unit "Santé UR12SP28”: Epidemiologic transition and prevention of chronic disease of the Ministry of Higher Education (Tunisia).

\section{References}

[1] Alwan, A. (2011) Global Status Report on Noncommunicable Diseases 2010. World Health Organization, Geneva. 
[2] Strong, K., Mathers, C., Leeder, S. and Beaglehole, R. (2005) Preventing Chronic Diseases: How Many Lives Can We Save. Lancet, 366, 1578-1582. http://dx.doi.org/10.1016/S0140-6736(05)67341-2

[3] Omran, A.R. (1971) The Epidemiological Transition: A Theory of the Epidemiology of Population Change. The Milbank Memorial Fund Quarterly, 49, 509-538. http://dx.doi.org/10.2307/3349375

[4] Ghannem, H., Maarouf, R., Tabka, A., et al. (1993) La triade obésité, hypertension et troubles de la glycoregulation dans une population semi-urbaine du Sahel Tunisien. Diabetes \& Metabolism, 19, 310-314.

[5] Henry-Amar, M., Papoz, L., Ben Khalifa, F., et al. (1981) Prevalence of Diabetes in a Random Sample from the Gouvernorat of Tunis. Revue d Épidémiologie et de Santé Publique, 29, 1-13.

[6] Hajem, S. (2012) Le système national d’information sur les causes de décès: Composante et principaux résultats pour l'année 2009. Publication de l’Institut National de Santé Publique, Tunis.

[7] Saidi, O., Ben Mansour, N., O’Flaherty, M., Capewell, S., Critchley, J.A. and Ben Romdhane, H. (2013) Analyzing Recent Coronary Heart Disease Mortality Trends in Tunisia between 1997 and 2009. PLoS One, 8, e63202. http://dx.doi.org/10.1371/journal.pone.0063202

[8] Ghannem, H. (2011) The Need for Capacity Building to Prevent Chronic Diseases in North Africa and the Middle East. Eastern Mediterranean Health Journal, 17, 630-632.

[9] Protocol and Guidelines: Countrywide Integrated Non Communicable Diseases Intervention (CINDI) Programme. Copenhagen, WHO Regional Office for Europe, 1996.

[10] World Health Organization (2005) Preventing Chronic Diseases: A Vital Investment. WHO, Geneva.

[11] Rose, G., Khaw, K. and Marmot, M. (2008) Rose’s Strategy of Preventive Medicine. Oxford University Press, New York. http://dx.doi.org/10.1093/acprof:oso/9780192630971.001.0001

[12] Fortmann, S.P., Williams, P.T., Hulley, S.B., Haskell, W.L. and Farquhar, J.W. (1981) Effect of Health Education on Dietary Behavior: The Stanford 3 Community Study. The American Journal of Clinical Nutrition, 34, 2030-2038.

[13] Mittelmark, M.B., Luepker, R.V., Jacobs, D.R., Bracht, N.F., Carlaw, R.W., Crow, R.S., et al. (1986) CommunityWide Prevention and Cardiovascular Disease: Education Strategies of the Minnesota Heart Health Program. Preventive Medicine, 15, 1-17. http://dx.doi.org/10.1016/0091-7435(86)90031-9

[14] Lefebvre, R.C., Lasater, T.M., Assaf, A.R. and Carleton, R.A. (1988) Pawtucket Heart Health Program: The Process of Stimulating Community Change. Scandinavian Journal of Primary Health Care. Supplement, 1, 31-37.

[15] Baghaei, A., Sarrafzadegan, N., Rabiei, K., Gharipour, M., Tavasoli, A.A., Shirani, S., et al. (2010) How Effective Are Strategies for Non Communicable Disease Prevention and Control in a High Risk Population in a Developing Country? Isfahan Healthy Heart Programme. Archives of Medical Science, 6, 24-31. http://dx.doi.org/10.5114/aoms.2010.13503

[16] Brownson, R.C., Riley, P. and Bruce, T.A. (1998) Demonstration Projects in Community-Based Prevention. Journal of Public Health Management \& Practice, 4, 66-77. http://dx.doi.org/10.1097/00124784-199803000-00009

[17] Sellers, D.E., Crawford, S.L., Bullock, K. and Mckinlay, J.B. (1997) Understanding the Variability in the Effectiveness of Community Heart Health Program: A Meta-Analysis. Social Science \& Medicine, 44, 1325-1339. http://dx.doi.org/10.1016/S0277-9536(96)00263-8

[18] Vartiainen, E., Laatikainen, T., Peltonen, M., Juolevi, A., Männistö, S., Sundvall, J., Jousilahti, P., Salomaa, V., Valsta, L. and Puska, P. (2010) Thirty-Five-Year Trends in Cardiovascular Risk Factors in Finland. International Journal of Epidemiology, 39, 504-518. http://dx.doi.org/10.1093/ije/dyp330

[19] Cole, T.J., Bellizzi, M.C., Flegal, K.M. and Dietz, W.H. (2000) Establishing a Standard Definition for Child Overweight and Obesity Worldwide: International Survey. BMJ, 320, 1240. http://dx.doi.org/10.1136/bmj.320.7244.1240

[20] Warren, C.W., Jones, N.R., Eriksen, M.P. and Asma, S. (2006) Patterns of Global Tobacco Use in Young People and Implications for Future Chronic Disease Burden in Adults. Lancet, 367, 749-753. http://dx.doi.org/10.1016/S0140-6736(06)68192-0

[21] World Health Organization (2011) Global Recommendation on Physical Activity for Health. http://www.who.int/dietphysicalactivity/physical-activity-recommendations-5-17years.pdf?ua=1 http://www.who.int/dietphysicalactivity/physical-activity-recommendations-18-64years.pdf

[22] Shea, S. and Basch, C.E. (1990) A Review of Five Major Community-Based Cardiovascular Disease Prevention Programs. Part I: Rationale, Design, and Theoretical Framework. American Journal of Health Promotion, 4, 203-213. http://dx.doi.org/10.4278/0890-1171-4.3.203

[23] Wilkinson, R. and Marmot, M., (Eds.), World Health Organization (2003) Social Determinants of Health. The Solid Facts. 2nd Edition, WHO, Geneva.

[24] Vartiainen, E., Puska, P., Pallonen, U. and Pöyhiä, P. (1982) Effects of Two Years’ Educational Intervention on Dietary Habits, Serum Cholesterol and Blood Pressure among 13 to 15 Year Old Adolescents. The North Karelia Youth 
Project. Acta Cardiologica, 37, 199-220.

[25] Sanderson, D.M., Ekholm, O., Hundrup, Y.A. and Rasmussen, N.K. (2005) Influence of Lifestyle, Health, and Work Environment on Smoking Cessation among Danish Nurses Followed Over 6 Years. Preventive Medicine, 41, 757-760. http://dx.doi.org/10.1016/j.ypmed.2005.06.002

[26] Schulte, P.A., Wagner, G.R., Downes, A. and Miller, D.B. (2008) A Framework for the Concurrent Consideration of Occupational Hazards and Obesity. The Annals of Occupational Hygiene, 52, 555-566. http://dx.doi.org/10.1093/annhyg/men055

[27] World Health Organization (1988) Expert Committee on Health Promotion in the Work Setting. Health Promotion for Working Populations. WHO, Geneva.

[28] Pelletier, K.R. (2001) A Review and Analysis of the Clinical and Cost-Effectiveness Studies of Comprehensive Health Promotion and Disease Management Program at the Worksite: 1998-2000 Update. American Journal of Health Promotion, 16, 107-116. http://dx.doi.org/10.4278/0890-1171-16.2.107

[29] Aldana, S.G. (2001) Financial Impact of Health Promotion Programs: A Comprehensive Review of the Literature. American Journal of Health Promotion, 15, 296-320. http://dx.doi.org/10.4278/0890-1171-15.5.296

[30] Harden, A., Peersman, G., Oliver, S., Mauthner, M. and Oakley, A. (1999) A Systematic Review of the Effectiveness of Health Promotion Interventions in the Workplace. Occupational Medicine, 49, 540-548. http://dx.doi.org/10.1093/occmed/49.8.540

[31] Wilson, M.G., Holman, P.B. and Hammock, A. (1996) A Comprehensive Review of the Effects of Worksite Health Promotion on Health Related Outcomes. American Journal of Health Promotion, 10, 429-435. http://dx.doi.org/10.4278/0890-1171-10.6.429

[32] Health and Welfare Canada (1992) Heart Health Equality: Mobilizing Communities for Action. Supply and Services Canada, Cat, Ottawa, No. H39-245/1992E.

[33] Rose, G. and Day, S. (1990) The Population Mean Predicts the Number of Deviant Individuals. BMJ, 301, $1031-1034$. http://dx.doi.org/10.1136/bmj.301.6759.1031 